\title{
Shifting institutional roles in biomedical innovation in a learning healthcare system
}

\author{
REBECCA S. EISENBERG* \\ Robert and Barbara Luciano Professor of Law, University of Michigan Law School, Ann Arbor, MI, USA
}

\begin{abstract}
The use of information technology in healthcare has accelerated progress toward the long-term goal of a learning healthcare system, in which data from prior clinical experience provides an ever-expanding resource to guide continuous improvements in health care. Although still in its early stages, the use of data from clinical experience to supplement data from premarket testing is changing the roles of Food and Drug Administration (FDA) and public and private health insurers in healthcare innovation and technology assessment. It could change who decides what research questions to pursue, whose evidentiary standards decide what counts as actionable knowledge, and who pays the costs of research. The shape and direction of resulting changes will depend on which actors and institutions decide to step forward and claim a larger role in healthcare innovation in response to technological and regulatory change.
\end{abstract}

A long-term goal of health policy makers is a learning healthcare system, a term of art in the health policy literature for an institutional structure in which records of past treatments and health outcomes provide an ongoing source of data to guide continuous improvements in healthcare (Institute of Medicine 2011). Ambitious visions for such a system allow doctors to consult data from prior records in real time at the point of care and incorporate precision medicine - treatment and prevention strategies that take into account individual patient variability - in order to optimize choices for each patient (Institute of Medicine 2007). There are many obstacles to the full implementation of such a system, including limitations on access, the quality and interoperability of electronic health records, and limits on the capacity of caregivers to make sense of the data available to them. Nonetheless, a more modest version of a learning healthcare system is gradually taking shape as researchers, lawmakers, and regulators seek to harness and analyze data from health records to improve healthcare and to lower its costs (Institute of Medicine 2010).

The ongoing shift toward a learning healthcare system has significant implications for the funding, utilization, and regulation of biomedical

*Email: rse@umich.edu 
innovation. Learning systems may differ in their organization of conjectures of how to improve healthcare and their organization of processes for evaluating alternative healthcare technologies. By harnessing new sources of knowledge about the health effects of medical technologies, a learning healthcare system makes it unnecessary to rely solely on data from premarket testing, which is typically funded and controlled by product-developing firms, and invites a larger role for other institutions that can participate in observational studies linked to clinical practice. It thus opens the door to a significant reorientation in the roles of institutions that drive healthcare innovation. It could change who decides what research questions to pursue, whose evidentiary standards determine what counts as actionable knowledge, and who pays the costs of research.

Institutional and evolutionary economics may provide useful perspectives for understanding these changes (Hodgson 2008; Nelson et al. 2011). Drawing on insights from the philosophy of science, these literatures recognize that human knowledge is inevitably incomplete, conjectural and fallible (Harper 1996; Loasby 1999). This is surely true of medicine, a field in which biological complexity and heterogeneity in the patient population combine with cognitive limitations to make optimal care an elusive goal (Gelijns et al. 2001). Caregivers will make different conjectures about how to proceed, guided by their own prior experiences and patterns of communication with others. In medicine as in other fields, some conjectures will do better than others, making it possible to improve performance over time through selection processes. Learning occurs when individuals and organizations acquire and process information, regardless of benefit, but the goal of learning is typically performance improvement (Argyris and Schön 1996). This is thus surely the goal of a learning healthcare system.

Selection mechanisms in healthcare reflect the choices of public and private gatekeepers, including regulators that decide what new products may enter the market and insurers that decide what they are willing to pay for. This makes the formulation and testing of conjectures a more formal and explicit process than it might be in fields without regulators and third-party payers, at least for new technologies. But even after new technologies enter clinical practice, much uncertainty remains about how best to use them and whether they should be modified, leaving much to learn through informal trial and error (Gelijns and Rosenberg 1994).

An important premise of evolutionary economics is that variety is essential to allow selection mechanisms to operate (Loasby 2001). Selection through human choices requires identifying problems, generating a variety of conjectures about how to address them, and selecting those conjectures that perform better while rejecting those that appear inferior on the basis of experience and analysis (Harper 1996). Gelijns et al. (2001) describe technological innovation in medicine as involving a coevolution of scientific understanding and clinical technique through the combined efforts of academic scientists, commercial firms, and clinical caregivers. In this account new problems come into view 
through new scientific understanding of the molecular bases of disease that identify new therapeutic targets. Academic medical centers and, increasingly, private contract research organizations supply the clinicians and patients that are necessary to evaluate and refine new products and to develop the data to support FDA approval and insurance coverage (Gelijns and Thier 2002). Incremental improvement and discoveries of new uses may follow as clinical use reveals further information about effects in patients (Gelijns and Rosenberg 1994).

Champions of a learning healthcare system highlight its potential to make variations in care and outcomes more readily visible and available for analysis as electronic data. By documenting the treatment choices of large numbers of caregivers, a learning healthcare system could potentially codify and provide access to their accumulated wisdom about how to treat patients. But if a learning healthcare system is also to provide data for evaluating which treatments perform better than others, somebody needs to decide what queries to submit, and when the data justify selection, rejection, or modification of prior approaches. The shape and direction of resulting changes in healthcare will depend on who decides to step forward and claim these roles.

Particularly important are the strategies of the public and private insurers that pay for healthcare. Health insurers are custodians of large volumes of data that could be used to evaluate the conjectures reflected in current healthcare practices. Moreover, by determining what they will pay for, insurers can control how healthcare is performed and how it is documented. Health insurers might be expected to bring a different set of priorities than product-developing firms to choices about what problems a learning healthcare system should address, perhaps placing greater emphasis on cost reduction (Gelijns et al. 2001).

In the past health insurers have often sought to avoid rather than enlarge their role in innovation. They have tried to maintain a distinction between experimentation and the provision of reasonable and necessary healthcare, limiting coverage to the latter, while declining to pay for the experimentation that precedes the incorporation of new technologies into the standard of care (Black 2007; Lahr 1995; Steinberg et al. 1995). This distinction may always have been something of an illusion (Gelijns et al. 2001). By repurposing healthcare records as data, a learning healthcare system further blurs the distinction. At the same time, it invites insurers to take advantage of their position as data custodians to pursue observational studies. If they adapt to this changing environment by assuming a larger role in data analysis and technology assessment, they could find opportunities to lower costs. But this would require departure from the time-honored strategy that has guided them in the past of declining to pay for research.

Standard neoclassical economic analysis offers a plausible explanation for the reluctance of insurers to invest in research: the resulting improvements in healthcare are "public goods" that insurers cannot readily exploit without 
disclosing them to the medical community, thereby sharing the benefits with competitors (Danzon and Nicholson 2012; Scotchmer 2004). Firms that introduce new health products to the market might solve this problem with patents, but firms that analyze healthcare records to determine which available treatments perform better than others cannot patent the superior treatments because they are no longer new (Eisenberg and Price 2017). This focus on public goods and patents may be useful in understanding incentives for new drug development. But it fails to account for the ongoing interplay between healthcare and health innovation in an integrated, dynamic learning system that continuously changes through interactions and feedback mechanisms between research and clinical care (Consoli and Mina 2009). A broader view must also take account of the important roles of regulators and payers in selecting healthcare technologies.

This essay sets the stage for such an analysis by considering some of the ways in which the transition to a learning healthcare system changes the roles of institutions that shape biomedical innovation and practice, with a focus on regulatory gatekeepers and public and private insurers. Section 1 provides a brief introduction to shifts over time in evidentiary standards and institutional mechanisms for evaluating healthcare technology. Section 2 examines more closely changes in requirements for FDA approval of new technologies as safe and effective toward greater reliance on postapproval studies and monitoring. Section 3 describes changes in how public and private insurers making coverage determinations engage in technology assessment, and considers how they might benefit from taking on a larger role in a learning healthcare system.

\section{Shifting evidentiary standards for evaluating healthcare technology}

Although patients are the ultimate consumers of medical technologies, they typically rely on others to choose appropriate technologies for them, beginning with doctors and other caregivers. The standards of caregivers are neither the only nor the most demanding obstacle to selection of new healthcare technologies. Indeed, the celebration of "evidence-based medicine" (EBM) as a new paradigm over the past quarter-century implies displacement of prior clinical practice standards that rested on less empirical rigor (Evidence-Based Medicine Working Group 1992).

Lurking behind the prescriptions of caregivers are decisions of other gatekeepers that control the course of healthcare innovation. Developers of new technologies make choices about $\mathrm{R} \& \mathrm{D}$ investments in light of expectations about regulatory decisions (such as FDA approval) and coverage decisions of public and private insurers, as well as expected demand from patients and caregivers. Regulators use data analysis to assess which technologies to approve, while caregivers use clinical judgment informed by practical experience to choose which technologies to use for their patients. Payers often rely heavily on the decisions 
of regulators and caregivers in deciding which technologies are reasonable and necessary for patients.

Decades before the modern EBM movement, FDA worked with academic scientists to develop rigorous evidentiary standards for evaluating the safety and effectiveness of new drugs (Carpenter 2010). These standards bypassed the clinical judgments of the medical profession to incorporate new scientific disciplines, such as toxicology and clinical pharmacology, as well as new standards of assessment that required experimental protocols, use of controls, and randomization. Congress endorsed this approach by adopting statutory standards for FDA approval that measured the necessary showing from the perspective of "experts qualified by scientific training and experience to evaluate the effectiveness of the drug involved" (21 US Code $\mathbb{} 355(\mathrm{~d})$ ). The result was to remove some products from the market, notwithstanding medical testimony that they were generally considered safe and effective within the medical profession. ${ }^{1}$ But FDA has never claimed authority to regulate the practice of medicine, and new medical technologies that do not involve the sale of new drugs or devices are beyond the reach of its approval requirements (21 US Code $\$ 396)$.

The EBM movement sought to bring similar rigor to a broader range of treatment choices, supplementing medical custom, anecdote and intuition with literature searches and clinical guidelines based on systematic analyses of published clinical research (Guyatt 2000). EBM called for training caregivers to choose treatments on the basis of the best available evidence under a hierarchy that placed randomized controlled trials (RCTs) at the top and unsystematic clinical observations at the bottom. For products such as drugs that require premarket approval from FDA, the EBM hierarchy thus enhanced the impact of evidence controlled by product-developing firms relative to evidence available from other sources (Evidence Based Medicine Renaissance Group 2014). Even when data from RCTs are available, they may provide limited guidance for treating diverse patient populations that differ from studied populations in medically significant ways (Silverman 2009). For therapeutic interventions such as medical and surgical procedures that FDA does not regulate, data from RCTs are often unavailable (Garber 2001).

An important goal of EBM was to improve patient outcomes by standardizing medical care in accordance with clinical guidelines based on the best available evidence (Eddy 2005). From an evolutionary perspective, although guidelines may allow practitioners to benefit from the knowledge and experience of others, standardization threatens to reduce the variety of clinical experience that might otherwise lead to better future selections (Gelijns et al. 2001; Loasby 1999). Too strict an injunction that medical practice should follow the findings of prior research ignores the important role of innovative caregivers in informing medical researchers as well as learning from them (Gelijns and Rosenberg 1994; Nelson

1 United States v. 50 Boxes More or Less, 909 F.2d 24 (1 $1^{\text {st }}$ Cir. 1990). 
et al. 2011). Some doctors criticize EBM as a call for "cookbook medicine" that devalues their skill and judgment and leaves too little room for adjusting treatment choices in light of variations in patient responses and preferences (Timmermans and Mauck 2005).

Critics have charged that insurers and hospitals use EBM more to control costs than to improve care (Biller-Adorno et al. 2004). Cost-conscious insurers may welcome EBM as a justification for refusing to pay for costly interventions that are not yet supported by rigorous studies, but the effect may be to stifle rather than promote innovation in areas that are less regulated and therefore less rigorously studied. Moreover, for regulated technologies insurers concerned about cost control may find that the published literature provides little evidence to answer their own questions about cost-effectiveness and comparative effectiveness that are of less interest to regulatory gatekeepers than they are to payers.

Public and private insurers have supported EBM through affiliated institutions that review evidence from published studies and formulate clinical practice guidelines (Blue Cross Blue Shield Association 2016; Garber 2001; Sullivan et al. 2009). Some insurers provide further support for EBM through paid access to reviews performed by professional societies and other external health technology assessment organizations (Trosman et al. 2011). To the extent that these organizations rely on literature reviews, they can provide at best a lagging assessment of the state of the art that relies heavily on evidence generated in response to the standards of other gatekeepers such as FDA.

The rise of precision medicine presents new opportunities and challenges for EBM. EBM-based clinical practice guidelines have always been constrained by the reality that the response of individual patients may differ from what the data predict for the average patient (Kravitz et al. 2004). Early proponents of EBM recognized this problem and contemplated an ongoing role for clinical expertise alongside review of scientific evidence in guiding treatment choices for patients (Sackett et al. 1996). Precision medicine offers more rigorous strategies for incorporating patient heterogeneity into clinical decisions, taking into account differences in genetics and other factors (Collins and Varmus 2015). It incorporates better diagnostic information, new biological insights, and data analysis based on sophisticated bioinformatics tools rather than intuitive clinical judgment (Beckmann and Lew 2016). It promises to transform conventional taxonomies of disease, revealing underlying differences between patients that account for differences in treatment response (National Research Council 2011). Because precision medicine leverages the power of large data sets to understand differences in clinical outcomes, it is likely to advance more rapidly in a learning healthcare system that generates data across large and diverse patient populations.

Meanwhile, a growing number of pharmaceutical products have been designed to work on particular molecular targets and approved for use in patients selected 
on the basis of genetic tests (Cohen and Felix 2014; FDA 2014a). The rise of targeted drug therapies has thus given FDA an important role in setting standards for precision medicine.

Although in the past rigorous standards for proving the effects of health technologies have often required costly clinical trials, advances in information technology offer the tantalizing prospect of evaluating healthcare technologies using rapidly accumulating health-related data derived outside traditional research settings. These new data sources include electronic health records, telemedicine, insurance claims and billing data, product and disease registries, and even health applications on personal devices and social media. These "realworld" data sources offer significant advantages as a supplement to data from RCTs conducted by product-developing firms (National Academies of Science, Engineering, and Medicine 2017). Repurposing health records as a data source might lower data collection costs and accelerate data accumulation by avoiding the cost of enrolling patients in trials, instead capturing data in the course of ordinary healthcare provision and record-keeping. All patients are potential sources of data, providing much larger data sets and more clinically relevant data. Healthcare records include data from a diverse patient population that includes people who might have been excluded from RCTs with strict enrollment criteria (e.g. patients with co-morbidities, patients who are taking or have taken other drugs, elderly patients, juvenile patients, pregnant patients), but whose clinical experience is nonetheless relevant to decisions that caregivers need to make in the real world. Data from these patients may inform questions that could not be answered (or have not been answered) through RCTs, given the high costs of RCTs and the incentives of the product-developing firms that pay for them to design RCTs to minimize the risk of failure (Bothwell et al. 2016). Larger data sets from more diverse patient populations may be particularly informative for personalized medicine, comparative effectiveness, observation of rare side effects, and observation of long-term effects (Eisenberg and Price 2017).

On the other hand, quality limitations for data generated outside of research settings may limit the questions they can answer (FDA 2017; Hoffman and Podgurski 2013). Busy clinicians may enter data incorrectly in EHRs, particularly when they are using systems with user interfaces designed by administrators to optimize billing rather than to collect research-quality data (Wachter 2015). Data collected in the course of treatment may lack crucial information for research purposes, such as health outcomes. Privacy concerns and informed consent present additional legal obstacles to the use of data collected for purposes of patient care for the different purpose of answering research questions (Evans 2012). Aggregating data collected by different people for different purposes using different systems introduces further problems of inconsistent coding and lack of interoperability (Eisenberg and Price 2017). Moreover, even large observational studies require cautious interpretation to avoid spurious causal inferences tainted by selection bias, confounding bias, and measurement bias (Gurwitz et al. 2005, 
Mamdani et al. 2005, Normand et al. 2005). It may be possible to address some of these sources of bias by adapting analytic approaches from traditional RCTs to the design of trials in real-world settings, including the use of prospectively planned interventions and randomization (Sherman et al. 2016).

Reliance on RCTs conducted by the private firms that develop and sell new technologies brings another source of bias into the knowledge base for healthcare (Naci et al. 2014), especially when the data are proprietary and not available for skeptical scrutiny by others. The sponsors of clinical trials make their own decisions about what to publish, allowing them to control the information available for technology assessment and EBM. An evidentiary hierarchy that favors RCTs over other data sources fortifies this advantage, while a shift toward greater reliance on other data sources opens the door for other institutions to play a larger role in informing technology assessment (Every-Palmer and Howick 2014). Healthcare records, although subject to privacy regulation and by no means freely available, are not created and controlled by product-developing firms. The institutions that maintain these records (e.g. insurers with custody of claims data) have different interests and incentives that could provide a counterweight to the interests of product-developing firms. Health insurers have interests in controlling healthcare costs that might lead them to pose different questions and to consider different interpretations than product-developing firms with an interest in promoting sales of their products (Gelijns et al. 2001). They may be more willing than product-developing firms to conclude that expensive new technologies are toxic, useless, or not worth their cost.

With encouragement from Congress, FDA has begun to provide guidance for a learning healthcare system on the advantages and limitations of these new data sources (FDA 2017; Sherman et al. 2016). It remains to be seen what role insurers will play. The next two sections examine more closely the roles of FDA and insurers in a learning healthcare system.

\section{The role of FDA in a learning healthcare system}

FDA regulation of drugs and some medical devices serves both a gatekeeper function, excluding new technologies from the market pending FDA approval, and a technology assessment function, marking successful completion of initial research to show safety and effectiveness (Eisenberg 2007). Prior to approval, developers of new technologies may not market their technologies, and therefore insurers need not decide whether to cover them. To get FDA approval, productdeveloping firms conduct premarket research in light of FDA's standards for showing safety and efficacy.

In the case of drugs, FDA standards have long favored randomized, placebocontrolled clinical trials, although other trial designs are possible and are increasingly likely to be accepted (Junod 2016; Temple and Ellenberg 2000; 21 Code of Federal Regulations $\mathbb{3} 314.126)$. FDA typically treats data from these 
trials as proprietary information belonging to the firms that paid for them and maintains them in confidence (Eisenberg 2011). FDA approval on the basis of data that are not publicly disclosed allows caregivers and insurers to rely on the assessment of a trusted intermediary without seeing the data for themselves. After FDA approval, firms may promote these products, and insurers will ordinarily pay for them without further assessment of whether they meet the usual coverage standard of reasonable and necessary care (Sachs 2016). In effect, insurers rely on FDA's determinations of safety and effectiveness, and caregivers' assessments of appropriateness for particular patients, to determine that new technologies have progressed beyond the experimental stage and constitute reasonable and necessary care.

The statutory provisions for approval of medical devices (21 US Code $\$ 360$ c et seq.), which were more recently added to the statute than most of the provisions for approval of new drugs (Medical Device Amendments 1976), direct FDA to rely less heavily on premarket testing, even for the relatively rare devices that require premarket approval (FDA 2015). In contrast to the more uniform and rigorous premarket review requirements for drugs, Congress adopted a riskbased stratified approach for regulating medical devices that reserves premarket approval requirements for only the highest-risk devices (Baumann 2012). Even for high-risk devices, the statute directs FDA to "consider whether the extent of data that otherwise would be required for approval of the application with respect to effectiveness can be reduced through reliance on postmarket controls" (21 US Code $\mathbb{S} 360 \mathrm{c}(\mathrm{a})(3)(\mathrm{C})$ ). A "least burdensome provision" in the statute mandates FDA to request only clinical data that are "necessary to establish device effectiveness" for premarket approval (21 US Code $\mathbb{S} 360 \mathrm{c}(\mathrm{a})(\mathrm{D})(2))$. These provisions challenge FDA to minimize reliance on premarket testing of new devices whenever it can instead approve products based on a preliminary showing with provision for ongoing postmarket data collection. FDA has issued guidance on the use of "real-world data" collected outside of traditional trials for regulatory decision-making for medical devices, indicating its views on when such data are of sufficient quality and reliability for its purposes (FDA 2017).

Most new medical devices avoid even this limited premarket approval requirement by relying on a statutory provision that substitutes a less onerous premarket notification process known as the " $510(\mathrm{k})$ process" (21 US Code $\mathbb{S} 360(\mathrm{k}))$ for devices shown to be "substantially equivalent" to previously approved devices (21 US Code $\$ 360 \mathrm{c}(\mathfrak{f})(1)(\mathrm{A})$ ). The lesser regulatory requirements for bringing these products to market make the imprimatur of FDA approval less meaningful for such devices than for drugs. For new technologies that may be marketed without FDA approval, such as new medical procedures and many laboratory-developed diagnostic tests, the marker of FDA approval is not available at all (Deverka and Dreyfus 2014).

Even for drugs, FDA has gradually shifted emphasis away from premarket testing toward greater reliance on postmarket studies. Congress has encouraged 
this development through legislation that promotes the use of healthcare records as data for regulatory purposes. A notable example is the FDA Sentinel System, implemented pursuant to a Congressional mandate in the Food and Drug Administration Amendments Act (2007) (FDAAA) in response to criticism of FDA's system for postmarket surveillance of the safety of previously approved products (US Government Accountability Office 2006). At the same time, FDAAA gave FDA significant new authorities to oversee the safety of drugs after approval (21 US Code $\mathbb{S} 355(\mathrm{o}), 355-1)$. This legislation encouraged a shift in the evidentiary basis for FDA decision-making away from sole reliance on data from premarket clinical trials and later adverse event reports submitted by drug companies toward new sources of data and expertise (Evans 2010). It directed FDA to collaborate with "public, academic, and private entities" to obtain access to "disparate data sources" and to "establish and maintain procedures for risk identification and analysis based on electronic health data" (21 US Code $\$ 355(\mathrm{k})(3)(\mathrm{B}),(\mathrm{C}))$. FDA has implemented this mandate by assembling the Sentinel System, a network of databases from over 50 healthcare organizations and academic institutions to which FDA can submit queries to evaluate product risks (Health Affairs Health Policy Brief 2015a).

Even as it expanded FDA's authority to require postapproval studies, FDAAA directed FDA to use these new authorities parsimoniously. It specified that FDA shall not require postapproval clinical trials unless it determines that less onerous postapproval studies will be insufficient, and shall not require postapproval studies unless it concludes that monitoring through adverse event reporting and the Sentinel System will be insufficient. (21 US Code $\$ 355(\mathrm{o})(3)(\mathrm{D})$ ). These provisions push FDA to question its traditional preference for RCTs and interventional studies and to consider when it might instead rely on the sort of postmarket monitoring and observational studies available in a learning healthcare system.

Congress has further downplayed the importance of premarket testing by codifying other FDA programs that accelerate approval of new drugs and biologics to address unmet medical needs for treatment of serious or lifethreatening conditions (FDA 2014b). To the extent that these programs allow approval of qualifying products on the basis of less onerous premarket trials, they leave more questions unanswered about the effects of these products at the time of approval. As a formal matter the standards of safety and effectiveness remain the same as for other products (21 US Code $\$ 356(\mathrm{e})(2)$ ). FDA thus commonly requires further postapproval studies to confirm the expected clinical benefits (FDA 2014b). FDA's expanded authority under FDAAA to impose postmarket controls and study requirements allow it to exercise its discretion to accelerate premarket approval while formally adhering to the same standards. Although these authorities include the possibility of requiring postmarket RCTs, the statute dictates a preference for monitoring through the Sentinel System or through observational studies when these less onerous methods would suffice (21 US Code $\mathbb{S} 355(\mathrm{k})(3)(\mathrm{B}),(\mathrm{C}))$. 
The $21^{\text {st }}$ Century Cures Act of 2016 (Cures Act) is even more explicit in its directives to FDA to shift its evidentiary focus for a variety of purposes toward postapproval observational studies and to ease the burden of premarket approval. The Cures Act requires FDA to develop a framework and guidance for evaluating "real-world evidence" to approve new indications for previously approved drugs and to satisfy postapproval study requirements, defining "realworld evidence" broadly to mean "data regarding the usage, or the potential benefits or risks, of a drug derived from sources other than randomized clinical trials." It requires FDA to "issue guidance addressing the use of complex adaptive and other novel trial design" for the review and approval of new drugs and biologic products (21 US Code $\mathbb{S} 35 \mathrm{~g}$ ).

A number of more specific provisions embrace the use of observational studies for particular kinds of products, including orphan drugs, regenerative medicine therapies, and "breakthrough" medical devices (21 US Code $\mathbb{S}$ 360ee $(b)(1)(C)$, $356(\mathrm{~g}), 360 \mathrm{e}-3)$. Although each of these provisions applies to a small subset of FDA's regulatory authorities, considered together they continue and expand a shift from reliance on rigorous enforcement of approval standards through premarket testing requirements toward accelerated initial approval followed by ongoing data collection after the product has entered clinical use.

Some critics have charged that shifting toward earlier FDA approval of new technologies based on less definitive premarket testing exposes more patients to risks that FDA might otherwise have protected them from if it continued to enforce more rigorous premarket RCT requirements (Raja 2016). On the other hand, some risks that do not show up in RCTs may be easier to observe in larger postmarket studies, allowing these risks to come to light more quickly if initial approval allows these studies to get under way sooner. The shift to a learning healthcare system challenges FDA to figure out how best to use the kinds of data that a learning healthcare system might provide alongside data from RCTs.

Accelerating the timing of FDA approval has another important consequence for insurers: it shifts the costs of new treatments from product-developing firms to insurers at an earlier stage in the continuum from research to standard of care. When FDA sets rigorous standards for premarket approval through data from RCTs, product-developing firms bear the cost of those trials, and insurers do not pay for these technologies until after FDA has decided that they are safe and effective. On the other hand, when FDA accepts a less definitive showing of safety and efficacy prior to approval, while continuing to monitor effects in postapproval data, costs may shift from product developers to healthcare payers at an earlier stage. Insurers might, perhaps, decline to cover products that are approved with a requirement for ongoing studies, on the theory that the intervention remains experimental as long as FDA continues to require further studies. But as postapproval data collection becomes more routine for a wider range of products, the distinction between experimental care and reasonable and necessary care is becoming less crisp than it was in the past. At a minimum, 
payers may find that the familiar marker of FDA approval no longer means what it used to. They might therefore need to reconsider their own role in technology assessment as they adapt to regulatory change.

\section{The role of health insurers in a learning healthcare system}

The role of health insurers in health-related technology assessment is shifting and uncertain (Eisenberg and Price 2017; Sachs 2016). In a provocative essay, Arrow (1963) identified the prevalence of risk, uncertainty and technical complexity as distinctive features of the market for healthcare that contribute to market failure, noting that "markets for the services of risk coverage are poorly developed or non-existent." Nearly 30 years later, looking back on a period of extraordinary expansion in medical technology, healthcare costs, and health insurance, Weisbrod (1991) built upon this basic insight to explain the dynamic interplay among these phenomena. In this account the expansion of public and private health insurance made possible rising expenditures on health care, which in turn increased the expected profitability of developing new medical technologies and accelerated investments in R\&D. The availability of costly new treatments further increased demand for health insurance, enlarging the expected market for future innovations and encouraging more R\&D. These developments have been more pronounced in the US than in other countries where payers have been more price-sensitive and more willing to use costeffectiveness metrics to allocate scarce resources (Towse and Sorenson 2012). Nonetheless, the importance of the US market to global innovation incentives (Lackdawalla and Sood 2012) invites a closer examination of the idiosyncratic features of the US healthcare system.

Multiple public and private insurers provide coverage of healthcare in the US under different applicable laws and contractual provisions. As a general matter, these rules and provisions oblige health insurers to cover items considered reasonable and necessary under the current standard of care, while allowing them to exclude items that remain experimental and unproven. As public and private payers have faced rising costs, expensive and unproven new technologies have sometimes become targets for cost control (Steinberg et al. 1995), justified by the logic of EBM. But the distinction between care that is reasonable and necessary and care that is experimental or unproven is breaking down in the transition to a learning healthcare system, in which healthcare delivery and research proceed in tandem rather than seriatim.

The largest healthcare payer in the US is the Medicare program, administered by the Centers for Medicare and Medicaid Services (CMS). Medicare provides healthcare coverage for people aged 65 and older under provisions of the US Social Security Act that prohibit payment for items and services that "are not reasonable and necessary for the diagnosis or treatment of illness or injury" (42

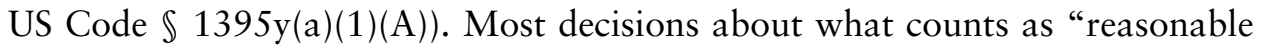


and necessary" for Medicare are made through local coverage determinations by private health insurers acting as Medicare Administrative Contractors (MACs) to process claims, but sometimes CMS makes a formal national coverage determination (NCD) that is binding on all of the regional MACs (42 US Code $\mathbb{S}$ $1395 \mathrm{ff}(\mathrm{f}))$. The NCD process provides for public notice and comment as well as for technology assessment from outside entities and deliberation by an advisory committee (Centers for Medicare and Medicaid Services 2013).

The Medicare "reasonable and necessary" standard is not necessarily the same as the FDA standards for safety and efficacy, and FDA approval does not necessarily entitle a technology to Medicare coverage (Chambers et al. 2015; Health Affairs Health Policy Brief 2015b). Although costs might seem pertinent to a determination of what is reasonable and necessary, CMS encounters considerable resistance when it says so (Neumann and Chambers 2012; Neumann 2004). Private insurers typically have provisions in health insurance contracts that are similar to the Medicare coverage limitations, and although they sometimes follow the lead of CMS when it makes an NCD, they need not do so (Chambers et al. 2015).

Sometimes mandates under federal or state law compel public and private healthcare payers to provide coverage of technologies that are FDA-approved or listed in certain compendia. For example, federal law requires state Medicaid programs that choose to cover prescription drugs (as they all do) to cover all FDA-approved drugs, with limited exceptions (42 US Code $\$ 1396 \mathrm{r}-8(\mathrm{~d})(2)(\mathrm{C})$ ). Medicare Part D provides for subsidized prescription drug coverage through private insurance plans that have some flexibility to determine which particular drugs within a therapeutic class to include in preferred formularies (42 US Code $\mathbb{S} 1395 \mathrm{w}-104(\mathrm{~b})(3))$. But federal law requires plans to cover all drugs approved by the FDA for certain indications (such as cancer), and to cover other indications for these same drugs supported by citations in certain compendia (42 US Code $\mathbb{S} 1395 \times(\mathrm{t})(2)(\mathrm{B})$, Centers for Medicare and Medicaid Services, Medicare Prescription Drug Manual, ch. 6, $\mathbb{S} 30.2 .5)$. The Patient Protection and Affordable Care Act of 2010 (ACA) requires prescription drug coverage as an essential benefit of private health insurance, while allowing some variation as to which members of a therapeutic class are covered and how much patients must pay out of pocket (Hutchins et al. 2013). State insurance laws may also require private insurers to cover certain categories of drugs (Ramsey 2015). These coverage mandates limit the significance of formal differences between FDA approval standards and insurance coverage standards when they apply. They also weaken the bargaining position of insurers in negotiating the prices they will pay for items that fall within coverage mandates.

There is more room for differences between approval and coverage standards for medical devices. Many medical devices get to market with little or no premarket scrutiny by FDA, leaving payers without meaningful signals from FDA to guide their determinations of whether new devices are reasonable and 
necessary (Feldman et al. 2008). Because FDA itself relies more heavily on postapproval data collection in the course of clinical care to ensure the safety and effectiveness of devices (FDA 2015), the evidentiary record for effective FDA oversight of these products depends on clinical use, which in turn may depend on favorable coverage determinations by payers. This could trap new technologies in a Catch-22, in which coverage determinations must await an evidentiary showing that is delayed by a lack of real-world data collection in the course of clinical care, which in turn is delayed by a lack of coverage.

While still excluding coverage of experimental care as a formal matter, insurers have gradually taken on a larger share of research costs necessary to determine the clinical utility of new technologies, sometimes under compulsion.

The predecessor to CMS (the Health Care Finance Administration, or HCFA) at one time took the position that it lacked legal authority to provide coverage of medical expenses incurred for Medicare beneficiaries enrolled in clinical trials, even for routine items that would otherwise plainly fall within the scope of Medicare coverage if administered outside the context of a clinical trial (Institute of Medicine 2000). As a result, the Medicare population was underrepresented in clinical trials, leaving caregivers and payers with limited guidance about proper treatment (Unger et al. 2006). In 2000 President Clinton signed an executive memorandum directing the secretary of Health and Human Services to authorize Medicare reimbursement for routine patient care costs and costs associated with medical complications for Medicare patients participating in clinical trials (Clinton 2000). CMS implemented the directive in a Medicare NCD. ${ }^{2}$ The Medicare Prescription Drug, Improvement, and Modernization Act (2003) codified a similar rule for medical devices, authorizing Medicare reimbursement for routine costs of care for Medicare beneficiaries enrolled in studies of experimental and investigational medical devices under FDA-approved investigational device exemptions (42 US Code $\$ 1395 \mathrm{y}(\mathrm{m})$ ).

The Patient Protection and Affordable Care Act (2010) includes a minimum coverage standard with new requirements for private health insurers to cover routine costs for patients participating in clinical trials (42 US Code $\$ 300 \mathrm{gg}-8$, Martin et al. 2014). The mandate is limited to trials "in relation to ... cancer or other life-threatening disease" which are funded or approved by a federal agency or a qualified non-federal agency identified in NIH guidelines, and conducted under an investigational new drug application reviewed by the FDA or exempt from that requirement.

2 Department of Health and Human Services, Health Care Financing Administration, Medicare Coverage Issues Manual Transmittal 126 (September 19, 2000), https:/www.cms.gov/Regulationsand-Guidance/Guidance/Transmittals/Downloads/R126CIM.pdf; current version at Department of Health and Human Services, Centers for Medicare and Medicaid Services, Medicare National Coverage Determinations Manual Ch. 1, Pt. 4, Sec. 310.1, Routine Costs in Clinical Trials (effective July 9, 2007), https://www.cms.gov/Regulations-and-Guidance/Guidance/Transmittals/Downloads/R74NCD.pdf (both accessed March 5, 2018). 
These mandates respond to demand for more treatment options for patients with life-threatening diseases. But that is not their only effect. They also compel insurers to bear more of the patient care costs incurred during research, enabling data collection from patients who would not otherwise participate in clinical trials. Payers may ultimately benefit from broader and more clinically relevant data collection. This is particularly likely for Medicare, given that the Medicare population might otherwise be excluded from clinical trials. If costly new technologies have different effects on elderly patients than they do on younger patients, Medicare might want to know that.

CMS has sometimes used coverage determinations to support studies of new technologies through the mechanism of "coverage with evidence development" (CED) (Centers for Medicare and Medicaid Services 2014). Under CED, Medicare covers promising technologies of unproven value for patients enrolled in clinical trials or registries in order to provide additional evidence to evaluate these technologies. Studies supported by CED have saved both costs and lives by producing data that prevented promising but unproven (and ultimately harmful) treatments from becoming the standard of care. An early success for this approach was the use of CED to evaluate the effects of lung volume reduction surgery for chronic obstructive lung disease, leading to the conclusion that the procedure was appropriate (and would be covered) for only a subset of the patient population (Centers for Medicare and Medicaid Services 2003).

The legal authority for CED presented something of a dilemma for CMS in view of its interpretation of the statutory language "reasonable and necessary" care as excluding experimental and investigational care. ${ }^{3}$ Ultimately CMS concluded that it had authority to support CED under another statutory provision allowing it to provide coverage in support of research supported by the Agency for Healthcare Research and Quality (AHRQ) (42 US Code $\$ 1395 \mathrm{y}(\mathrm{a})(1)(\mathrm{E}))$. AHRQ has authority to conduct and support research to identify the most effective and appropriate means to prevent, diagnose, treat, and manage diseases, disorders, and other health conditions, with a specific mandate to reflect the needs and priorities of the Medicare program (42 US Code $\mathbb{S} 1320 \mathrm{~b}-12$ ). AHRQ does not perform or fund the studies covered by CED itself, although it does review studies to determine whether they meet a list of requirements set forth in CMS guidance (Centers for Medicare and Medicaid Services 2014).

CED is an administrative innovation that shifts some research costs on to Medicare to provide at least limited coverage of technologies that it might otherwise decline to cover on the ground that available evidence does not yet

3 The statutory language appears at 42 US Code $\$ 1395 \mathrm{y}(\mathrm{a})(1)(\mathrm{A})$, prohibiting payment for items or services "not reasonably necessary for the diagnosis or treatment of illness or injury or to improve the functioning of a malformed body member." The CMS interpretation appears at 42 Code of Federal Regulations $\mathbb{4} 411.15(\mathrm{o})$ (specifically excluding coverage of “experimental or investigational devices”). 
show them to be reasonable and necessary. CED may be a cost-effective use of CMS funding if the resulting data allow it to make better coverage determinations in the future, thereby avoiding costly overuse of technologies through better understanding of when they are reasonable and necessary.

Private insurers have also experimented with a similar mechanism for evaluating costly treatments of unproven value. An early success was the study of high-dose chemotherapy with autologous bone marrow transplant (HDCABMT) in patients with metastatic breast cancer in Blue Cross Blue Shield plans. The plans only covered the procedure for patients who agreed to participate in trials, triggering public outcry against the plans for withholding coverage from other patients because of the high costs of treatment (Mohr and Tunis 2010). Eventually, however, the studies showed that HDC-ABMT increased the risk of death, preventing a costly and lethal procedure from becoming the standard of care.

These experiments with CED are small, tentative steps toward greater involvement of insurers in a learning healthcare system. So far, they have focused on technologies such as surgical procedures that FDA either does not regulate or makes available for clinical use with only minimal prior technology assessment. As FDA increasingly relies on postapproval oversight and real-world evidence to ensure that regulated products are safe and effective, CED may make sense for a larger share of new technologies. It represents a middle ground between two problematic alternatives: (1) continuing to accept FDA approval as a proxy for reasonable and necessary care, as FDA approval standards allow more products to get to market with fewer demands for premarket testing; and (2) refusing to provide coverage for these more easily approved technologies until their sponsors can produce better evidence (beyond what FDA requires at the premarket stage) to support their safety and efficacy. The first alternative would effectively expand insurance coverage for unproven technologies by ignoring the changing meaning of FDA approval, while the second would slow or halt effective technology assessment by preventing the clinical use that is necessary for data collection.

Health insurers may ultimately need to take a larger role in evaluating healthcare technologies for a learning healthcare system to succeed. First, for costly new technologies, insurance coverage will be necessary in order to generate data from clinical use. A learning healthcare system can only study the data that are recorded in the course of healthcare delivery, and healthcare is unlikely to be delivered on a broad scale without insurance coverage. Without coverage, data collection will be limited to the smaller and less representative data generated by technology developing firms in the course of clinical trials. Second, insurers are custodians of large amounts of data, giving them an advantage over other potential data analysts who must first negotiate with insurers to get access to data (although insurers may need to acquire new capabilities in data analytics to exploit this advantage). Insurers can and do transfer or sell their data to others, but such transfers raise problems of privacy and informed consent that might be 
minimized if payers were to bring the relevant data analysis expertise in-house (Terry 2014). Third, insurers can use their power as payers to encourage the collection of data that will make healthcare records more informative.

If they took a larger role in a learning healthcare system, health insurers could consider what questions they would like to answer and devise strategies to collect the right data, rather than relying on other parties to decide what data to collect and reveal. Insurers might have more interest than product-developing firms or caregivers in learning how to avoid wasteful overuse of costly new technologies. If health insurers sought to benefit from the use of EHRs as data, perhaps they would make it worthwhile for caregivers to keep records that are more useful and informative for a learning healthcare system, such as better diagnostic information and better information on patient experience and outcomes. Health insurers have different incentives than the caregivers that submit bills to them, just as they have different incentives than product-developing firms. Insurers should not want to depend solely on the data generated by those who seek to prosper from increasing healthcare costs as they make decisions about what care is reasonable and necessary (Eisenberg and Price 2017). These differences in incentives could make payers a useful counterweight to caregivers and product developers in medical technology assessment.

On the other hand, payers may find it harder to profit from investments in healthcare research and data analysis than product-developing firms. If analysis of health records reveals that a new technology is unsafe or ineffective, or should only be used for certain patients or indications, payers may need to publish that information in order to change the standard of care, thereby making it freely available to their competitors. Blue Cross Blue Shield was not the only firm to benefit from learning about the effects of HDC-ABMT. Although productdeveloping firms often rely on patents on new products to derive a competitive advantage from $R \& D$, payers that invest in evaluating technologies that are already in use are unlikely to be able to patent their results. The patent system rewards novelty, not selection. Finally, even when analysis of healthcare data allows payers to save costs, their incentives for cost-savings may be diminished if they are able to pass on higher costs to employers and insurance holders, further limiting the benefits they gain from learning how to deploy healthcare more economically.

CMS may be better motivated to invest in a learning healthcare system than private insurers. As a single payer for Medicare, CMS might be better able to capture the benefits of observational studies of treatment effects in elderly patients to the extent that age is a significant predictor of treatment response. Moreover, as the healthcare payer for over 100 million Americans, CMS generates data on a larger scale than any other payer (Brennan et al. 2014), and its public health mission might make CMS less averse to providing spillover benefits for other payers from studies it supports. Medicare cannot easily pass on rising costs to patients, but relies on a reluctant Congress to expand its resources. 
This could give it better incentives than private insurers to pay for studies that will show how to save on healthcare costs, provided it has the legal authority to do so.

CMS may be hampered by a tradition of at least formally ignoring costeffectiveness in making coverage determinations, even as the fiscal solvency of the program deteriorates (Neumann et al. 2005). Although Congress has sometimes supported comparative effectiveness research to determine how different therapies compare with one another, proposals to allow explicit consideration of costs have failed in the face of persistent political opposition (Neumann 2004). Meanwhile cost-effectiveness research proceeds in institutions that are less constrained by the politics of healthcare in the US, including the National Institute for Health and Care Excellence (NICE) in the UK (https://www.nice.org.uk) and the Institute for Quality and Efficiency in Health Care in Germany (https://www.iqwig.de/en/home.2724.html). But costeffectiveness analysis turns on prices that often differ for the same technology across different countries for a variety of reasons, including differences in how they pay for healthcare.

Even without explicit consideration of cost-effectiveness, analysis of healthcare data might reduce costs of future care by identifying those patients who are unlikely to benefit from particular treatment interventions. But CMS might worry ex ante that such studies could raise future costs by identifying additional patients who might benefit from further treatment as easily as it could lower them. If that is what they expect, they might see little reason to support the shift toward a learning healthcare system, and considerable reason to resist it.

\section{Conclusion}

Improvements in information technology and data analytics have combined with improved understanding of individual variation in disease and treatment response to promote interest in a learning healthcare system that uses evidence collected in the course of clinical care to study the effects of healthcare technologies. A learning healthcare system could potentially make more broadly visible the treatment choices of many different caregivers and patients, allowing data analysts to make more informed selections from among the variety of clinical conjectures that these choices represent. It matters who controls and uses these data, because different analysts might seek answers to different questions with different evidentiary standards. A learning healthcare system breaks down the distinction long maintained by health insurers between experimental care and clinically validated care that has become reasonable and necessary. The line between research and reasonable and necessary healthcare is gradually collapsing as health records, patient registries and insurance claims data provide an everexpanding data resource for evaluating new and old technologies.

The transformation is apparent at FDA, which has been gradually shifting the evidentiary basis for its regulatory decisions about an expanding list of 
technologies from reliance on premarket RCTs to earlier approval coupled with ongoing postapproval studies. Public and private insurers also face growing pressure to adapt. Although they continue to exclude coverage for experimental care, they face legal mandates to provide coverage of routine healthcare costs for patients enrolled in clinical trials. Moreover, on their own initiative they have sometimes chosen to provide coverage of promising technologies for patients enrolled in clinical trials or registries designed for further data collection.

Viewed from the perspective of an older order in which experimentation largely precedes use in the course of clinical care, these changes enlarge the financial burden on insurers at a time of rising healthcare costs, shifting the costs of new technologies to them at an earlier stage when their effects remain unproven. On the other hand, the transition to a learning healthcare system presents opportunities for insurers to take a larger role in determining what questions the system can ask and answer. Insurers have custody of large quantities of health data that might reveal how to use costly technologies more parsimoniously, avoiding waste and improving health outcomes. They also control the data that the healthcare system generates through their decisions about what they will cover and what documentation they will require for payment. Those who pay for healthcare have different incentives than the caregivers and product-developing firms that submit bills to them, giving insurers good reason to take a more active role in analyzing the data available for technology assessment. The availability and quality of these data may depend on the willingness of insurers to embrace a learning healthcare system, not only by paying its costs, but by determining what it should learn.

\section{Legislation}

$21^{\text {st }}$ Century Cures Act (2016), Pub. L. No. 114-255 $\$ 3022$, codified at 21 US Code $\$ 355 \mathrm{~g}$. Patient Protection and Affordable Care Act (2010), Pub. L. No. 111-48, 124 Stat. 119.

Food and Drug Administration Amendments Act (2007), Pub. L. No. 110-85, 121 Stat. 823. Medicare Prescription Drug, Improvement, and Modernization Act (2003) Pub. L. No. 10873, 117 Stat. 2066.

Medical Device Amendments (1976), Pub. L. No. 94-295, 90 Stat. 539.

\section{References}

Argyris, C. and D. Schön (1996), Organizational Learning II: Theory, Method and Practice, Reading, MA: Addison-Wesley.

Arrow, K. J. (1963), 'Uncertainty and the Welfare Economics of Medical Care', American Economic Review, 53(5): 941-973.

Baumann, J. (2012), 'The “Déjà vu Effect:” Evaluation of United States Medical Device Legislation, Regulation, and the Food and Drug Administration's Contentious 510(k) Program', Food and Drug Law Journal, 67(3): 337-361. 
Beckmann, J. S. and D. Lew (2016), 'Reconciling evidence-based medicine and precision in the era of big data: challenges and opportunities', Genome Medicine, 8: 134. doi 10.1186/s13073-016-1388-7.

Biller-Adorno, N., C. Lenk and J. Leititis (2004), 'Ethics, EBM and hospital management', Journal of Medical Ethics, 30(2): 136-140.

Black, L. (2007), 'Experimental Breast Cancer Treatments and Health Insurance Coverage', Virtual Mentor, 9(1): 34-7, available at http://journalofethics.ama-assn.org/ 2007/01/hlaw1-0701.html (accessed 5 March 2018).

Blue Cross Blue Shield Association (2016) 'Blue Cross Blue Shield Association Launches Evidence Street Website to Streamline Evaluations of Medical Devices, Diagnostics and Pharmaceuticals', available at https://www.bcbs.com/news/press-releases/ blue-cross-blue-shield-association-launches-evidence-street-website-streamline (accessed 5 March 2018).

Bothwell, L. E., J. A. Greene, S. H. Podolsky and D. S. Jones (2016), 'Assessing the Gold Standard - Lessons from the History of RCTs', New England Journal of Medicine, 374(22): 2175-2181.

Brennan, N., A. Oelschlaeger, C. Cox and M. Tavenner (2014), 'Leveraging the Big-Data Revolution: CMS Is Expanding Capabilities to Spur Health System Transformation', Health Affairs, 33(7): 1195-1202.

Carpenter, D. (2010), Reputation and Power: Organizational Image and Pharmaceutical Regulation at the FDA, Princeton, NJ: Princeton University Press, pp. 118227.

Centers for Medicare and Medicaid Services (2003) 'Decision for Lung Volume Reduction Surgery' (CAG 00115R), https://www.cms.gov/medicare-coverage-database/ details/nca-decision-memo.aspx? NCAId $=96 \& v e r=7 \& N c a N a m e=$ Lung + Volume + Reduction+Surgery $\&$ Search Type $=$ Advanced $\&$ CoverageSelection $=$ Both $\&$ NCSelection $=$ NCA $\% 7 C C A L \% 7 C N C D \% 7 C M E D C A C \% 7 C T A \% 7 C M C D \&$ ArticleType $=$ Ed $\% 7 C K e y \% 7 C S A D \% 7 C F A Q \& P o l i c y T y p e=$ Final\&s=-\%7C5\%7C6\% 7C66\%7C67\%7C9\%7C38\%7C63\%7C41\%7C64\%7C65\%7C44\&KeyWord= Lung+Volume+Reduction+Surgery\&KeyWordLookUp=Doc\&KeyWordSearchType $=$ And $\& \mathrm{kq}=$ true $\& \mathrm{bc}=$ IAAAABAAIAAA $\&$ (accessed 5 March 2018).

Centers for Medicare and Medicaid Services (2013), 'Medicare Program; Revised Process for Making National Coverage Determinations', Federal Register, 78(152): 48,164-169 (CMS 2013 NCD Process).

Centers for Medicare and Medicaid Services (2014) 'Guidance for the Public, Industry, and CMS Staff: Coverage with Evidence Development' (CMS 2014 CED Guidance), 20 November 2014, available at https://www.cms.gov/medicare-coveragedatabase/details/medicare-coverage-document-details.aspx?MCDId=27 (accessed 5 March 2018).

Centers for Medicare and Medicaid Services, Medicare Prescription Drug Manual, ch. 6, $\mathbb{S} 30.2 .5$, revised January 2016, available at https://www.cms.gov/Medicare/ Prescription-Drug-Coverage/PrescriptionDrugCovContra/Downloads/Part-D-BenefitsManual-Chapter-6.pdf (accessed 5 March 2018).

Chambers, J. D., M. Chenoweth, T. Thorat and P. J. Neumann (2015), 'Private Payers Disagree With Medicare Over Medical Device Coverage About Half The Time', Health Affairs, 34(8): 1376-1382.

Clinton, W. J. (2000), 'Memorandum on Increasing Participation of Medicare Beneficiaries in Clinical Trials', in Public Papers of the Presidents of the United States, William J. 
Clinton 2000-2001, Book 1, January 1-June 26, 2000, at 1107-9, Washington DC: National Archives and Records Administration, Office of the Federal Register.

Cohen, J. P. and A. E. Felix (2014), 'Personalized Medicine's Bottleneck: Diagnostic Test Evidence and Reimbursement', Journal of Personalized Medicine, 4(2): 163-175. doi:10.3390/jpm4020163.

Collins, F. S. and H. Varmus (2015), 'A New Initiative on Precision Medicine', New England Journal of Medicine, 372(9): 793-795.

Consoli, D. and A. Mina (2009), 'An Evolutionary Perspective on Health Innovation Systems', Journal of Evolutionary Economics, 19(2): 297-319.

Danzon, P. M. and S. Nicholson (eds) (2012), The Oxford Handbook of The Economics of the Biopharmaceutical Industry, Oxford: Oxford University Press.

Deverka, P. A. and J. C. Dreyfus (2014), 'Clinical Integration of Next Generation Sequencing: Coverage and Reimbursement Challenges', Journal of Law, Medicine \& Ethics, 42(s1): 22-41.

Eddy, D. M. (2005), 'Evidence-Based Medicine: A Unified Approach', Health Affairs, 24(1): 9-17.

Eisenberg, R. S. (2007), 'The Role of the FDA in Innovation Policy', Michigan Telecommunications \& Technology Law Review, 13(2): 345-388.

Eisenberg, R. S. (2011), 'Data Secrecy in the Age of Regulatory Exclusivity', in R. C. Dreyfuss and K. J. Strandburg (eds), The Law and Theory of Trade Secrecy, Northampton, MA: Edward Elgar, pp. 467-491.

Eisenberg, R. S. and W. N. Price II (2017), 'Promoting Healthcare Innovation on the Demand Side', Journal of Law Biosciences, 4(1): 3-49. doi: 10.1093/jlb/lsw062, at 16-27.

Evans, B. J. (2010), 'Seven Pillars of a New Evidentiary Paradigm: The Food, Drug, and Cosmetic Act Enters the Genomic Era', Notre Dame Law Review, 85(2): 419524.

Evans, B. J. (2012), 'The Ethics of Postmarketing Observational Studies of Drug Safety under Section 505 (o)(3) of the Food, Drug, and Cosmetic Act', American Journal of Law \& Medicine, 38(4): 577-606.

Every-Palmer, S. and J. Howick (2014), 'How Evidence-Based Medicine is Failing Due to Biased Trials and Selective Publication', Journal of Evaluation in Clinical Practice, 20(6): 908-914.

Evidence Based Medicine Renaissance Group (2014) 'Evidence Based Medicine: A Movement in Crisis?' British Medical Journal, 348: g3725, available at www.bmj.com/content/348/bmj.g3725 (accessed 5 March 2018).

Evidence-Based Medicine Working Group (1992), 'Evidence-Based Medicine: A New Approach to Teaching the Practice of Medicine', Journal of the American Medical Association, 268(17): 2420-2425.

FDA (2014a), ' In Vitro Companion Diagnostic Devices Guidance for Industry and Food and Drug Administration Staff', Food and Drug Administration.

FDA (2014b), 'Guidance for Industry: Expedited Programs for Serious Conditions - Drugs and Biologics', available at https:/www.fda.gov/downloads/Drugs/ Guidances/UCM358301.pdf (accessed 5 March 2018).

FDA-Food and Drug Administration (2015), 'Balancing Premarket and Postmarket Data Collection for Devices Subject to Premarket Approval, Guidance for Industry and Food and Drug Administration Staff', available at https://www.fda.gov/ downloads/medicaldevices/deviceregulationandguidance/guidancedocuments/ ucm393994.pdf (accessed 5 March 2018). 
FDA (2017), 'Use of Real-World Evidence to Support Regulatory DecisionMaking for Medical Devices: Guidance for Industry and Food and Drug Administration Staff' available at https:/www.fda.gov/downloads/medicaldevices/ deviceregulationandguidance/guidancedocuments/ucm513027.pdf (accessed 5 March 2018).

Feldman, J. D., A. J. Petersen, L. S. Karliner and J. A. Tice (2008), 'Who is Responsible for Evaluating the Safety and Effectiveness of Medical Devices? The Role of Independent Technology Assessment', Journal of General Internal Medicine, 23(Suppl. 1): 5763.

Garber, A. M. (2001), 'Evidence-Based Coverage Policy', Health Affairs, 20(5): 62-82.

Gelijns, A. and N. Rosenberg (1994), 'The Dynamics of Technological Change in Medicine', Health Affairs, 13(3): 28-46.

Gelijns, A. and S. Thier (2002), 'Medical Innovation and Institutional Interdependence: Rethinking University-Industry Connections', Journal of the American Medical Association, 287(1): 72-77.

Gelijns, A., J. G. Zivin and R. R. Nelson (2001), 'Uncertainty and Technological Change in Medicine', Journal of Health Politics, Policy and Law, 26(5): 913-924.

Gurwitz, J. H., K. Sykora, M. Mamdani, D. L. Streiner, S. Garfinkel, S. T. Normand, G. M. Anderson and P. A. Rochon (2005), 'Reader's guide to critical appraisal of cohort studies: 1. Role and Design', British Medical Journal, 330(7496): 895-897.

Guyatt, G. H., R. B. Haynes, R. Z. Jaeschke, L. Green, C. D. Naylor, M. C. Wilson and W. S. Richardson for the Evidence-Based Medicine Working Group (2000), 'Users' Guides to the Medical Literature XXV. Evidence-Based Medicine: Principles for Applying the Users' Guides to Patient Care', Journal of the American Medical Association, 284(10): 1290-1295.

Harper, D. (1996), Entrepreneurship and the Market Process. London: Routledge.

Health Affairs Health Policy Brief (2015a), The FDA's Sentinel Initiative, available at http://healthaffairs.org/healthpolicybriefs/brief_pdfs/healthpolicybrief_139.pdf (accessed 5 March 2018).

Health Affairs Health Policy Brief (2015b), Aligning FDA and CMS Review, available at https://www.healthaffairs.org/do/10.1377/hpb20150827.132391/full/ healthpolicybrief_143.pdf (accessed 5 March 2018).

Hodgson, G. M. (2008), 'An Institutional and Evolutionary Perspective on Health Economics', Cambridge Journal of Economics, 32(2): 235-256.

Hoffman, S. and A. Podgurski (2013), 'Big Bad Data: Law, Public Health and Biomedical Databases', Journal of Law, Medicine \& Ethics, 41(s1): 56-60.

Hutchins, V. A., M. B. Samuels, and A. M. Lively (2013), 'Analyzing the Affordable Care Act: Essential Health Benefits and Implications for Oncology', Journal of Oncology Practice, 9(2): 73-77.

Institute of Medicine (2000), Extending Medicare Reimbursement in Clinical Trials, Washington, DC: National Academies Press.

Institute of Medicine (2007), The Learning Healthcare System, Washington, DC: National Academies Press.

Institute of Medicine (2010), Clinical Data as the Basic Staple of Health Learning: Creating and Protecting a Public Good, Washington, DC: National Academies Press.

Institute of Medicine (2011), Digital Infrastructure for the Learning Health System: The Foundation for Continuous Improvement in Health and Health Care: Workshop Series Summary, Washington, DC: National Academies Press. 
Junod, S. W. (2016), 'FDA and Clinical Drug Trials: A Short History', available at https://www.fda.gov/aboutfda/whatwedo/history/overviews/ucm304485.htm (accessed 5 March 2018).

Kravitz, R. L., N. Duan and J. Braslow (2004), 'Evidence-Based Medicine, Heterogeneity of Treatment Effects, and the Trouble with Averages', Millbank Quarterly, 82(4): 661687.

Lahr, J. G. (1995), What Is the Method to Their "Madness"? Experimental Treatment Exclusions in Health Insurance Policies', Journal of Contemporary Health Law \& Policy, 13(2): 613-636.

Lakdawalla, D. and N. Sood (2012), 'Incentives to Innovate', in: P. M. Danzon and S. Nicholson (eds), The Oxford Handbook of Economics of the Biopharmaceutical Industry, Oxford: Oxford University Press, pp. 143-166.

Loasby, B. (1999), Knowledge, Institutions and Evolution in Economics, London and New York: Routledge.

Loasby, B. J. (2001) 'Time, Knowledge and Evolutionary Dynamics: Why Connections Matter', Journal of Evolutionary Economics, 11(4): 393-412.

Mamdani, M., K. Sykora, P. Li, D. L. Streiner, P. C. Austin, P. A. Rochon and G. M. Anderson (2005), 'Reader's Guide to Critical Appraisal of Cohort Studies: 2. Assessing the Potential for Confounding', British Medical Journal, 330(7497): 960962.

Martin, P. J., N. Davenport-Ennis, N. J. Petrelli, F. M. Stewart, F. R. Appelbaum and A. Benson III (2014) 'Responsibility for Costs Associated With Clinical Trials', Journal of Clinical Oncology, 32(3): 3357-3360.

Mohr, P. E. and S. R. Tunis (2010), 'Access with Evidence Development: The US Experience', Pharmacoeconomics, 28(2): 153-162.

Naci, H., S. Dias, and A. E. Ades (2014), 'Industry Sponsorship Bias in Research Findings: A Network Meta-Analysis of LDL Cholesterol Reduction in Randomised Trials of Statins', British Medical Journal, 349: g5741. doi: 10.1136/bmj.g5741, available at www.bmj.com/content/bmj/349/bmj.g5741.full.pdf (accessed 5 March 2018).

National Academies of Science, Engineering, and Medicine (2017), Real-World Evidence Generation and Evaluation of Therapeutics: Proceedings of a Workshop. Washington, DC: National Academies Press. doi: 10.17226/24685.

National Research Council (2011), Toward Precision Medicine: Building a Knowledge Network for Biomedical Research and a New Taxonomy of Disease, Washington, DC: National Academies Press.

Nelson, R. R., K. Buterbaugh, M. Perl and A. Gelijns (2011), 'How Medical Know-How Progresses', Research Policy, 40(10): 1339-1344.

Neumann, P. J. (2004), 'Why Don't Americans Use Cost-Effectiveness Analysis?' American Journal of Managed Care, 10: 308-312.

Neumann, P. J., A. B. Rosen, and M. C. Weinstein (2005), 'Medicare and Cost-Effectiveness Analysis', New England Journal of Medicine 353: 1516-1522.

Neumann, P. J. and J. D. Chambers (2012), 'Medicare's Enduring Struggle to Define "Reasonable and Necessary" Care', New England Journal of Medicine, 367: 17751777.

Normand, S. L., K. Sykora, P. Li, M. Mamdani, P. A. Rochon and G. M. Anderson (2005), 'Reader's Guide to Critical Appraisal of Cohort Studies: 3. Analytical Strategies to Reduce Confounding', British Medical Journal, 330(7498): 10211023. 
Raja, F. R. (2016), 'Evidentiary Standards for Drug Approvals in the $21^{\text {st }}$ Century Cures Act: A Continued Trend Towards Valuing Access Over Safety for Pharmaceutical Drugs', North Carolina Journal of Law and Technology, 18: 409-437.

Ramsey, S. D. (2015), 'How State and Federal Policies As Well As Advances In Genome Science Contribute To The High Cost of Cancer Drugs', Health Affairs 34(4): 571-575.

Sachs, R. R. (2016), 'Your Weekly Reminder That FDA Approval and Insurance Coverage Are Often Linked', Bill of Health blog (Harvard Law Petrie-Flom Center), available at http://blogs.harvard.edu/billofhealth/2016/11/30/your-weekly-reminder-that-fdaapproval-and-insurance-coverage-are-often-linked/ (accessed 5 March 2018).

Sackett, D. L., W. M. C. Rosenberg, J. A. Muir Gray, R. B. Haynes and W. S. Richardson (1996), 'Evidence Based Medicine: What It Is and What It Isn't', British Medical Journal, 312: 71-72.

Scotchmer, S. (2004), Innovation and Incentives, Cambridge, MA: MIT Press.

Sherman, R. E., S. A. Anderson, G. J. Dal Pan, G. W. Gray, T. Gross, N. L. Hunter, L. LaVange, D. Marinac-Dabic, P. W. Marks, M. A. Robb, J. Shuren and R. Temple (2016), 'Real-World Evidence - What Is It and What Can It Tell Us?' New England Journal of Medicine, 375(23): 2293-2297.

Silverman, S. L. (2009), 'From Randomized Controlled Trials to Observational Studies', American Journal of Medicine, 122(2): 114-120.

Steinberg, E. P., S. Tunis and D. Shapiro (1995), 'Insurance coverage for experimental technologies', Health Affairs, 14(4): 143-158.

Sullivan, S. D., J. Watkins, B. Sweet and S. D. Ramsey (2009), 'Health Technology Assessment in Health-Care Decisions in the United States', Value in Health, 12(Supp. 2): S39-S44.

Temple, R. and S. S. Ellenberg (2000), 'Placebo-controlled Trials and Active Control Trials in the Evaluation of New Treatments. Part I: Ethical and Scientific Issues', Annals of Internal Medicine, 133(6): 455-463.

Terry, N. P. (2014), 'Big Data Proxies and Health Data Exceptionalism', Health Matrix, 24: 65-108.

Timmermans, S. and A. Mauck (2005), 'The Promises and Pitfalls of Evidence-based Medicine', Health Affairs, 24(1): 18-28.

Towse, A. M. Drummon and C. Sorenson (2012), Measuring Value: Pharmacoeconomics Theory and Practice. In: P. M. Danzon and S. Nicholson (eds), The Oxford Handbook of Economics of the Biopharmaceutical Industry, Oxford: Oxford University Press, pp. 394-437.

Trosman, J. R., S. L. Van Bebber and K. A. Phillips (2011), 'Health Technology Assessment and Private Payers' Coverage of Personalized Medicine', Journal of Oncology Practice, 7(3S): 18s-24s.

US Government Accountability Office (2006), Report to Requesters: Drug Safety, Improvements Needed in FDA's Postmarket Decision-making and Oversight Process.

Unger, J. M., C. A. Coltman, J. J. Crowley, L. F. Hutchins, S. Martino, R. B. Livingston, J. S. Macdonald, C. D. Blanke, D. R. Gandara, E. D. Crawford and K. S. Albain (2006), 'Impact of the Year 2000 Medicare Policy Change on Older Patient Enrollment to Cancer Clinical Trials'. Journal of Clinical Oncology, 24(1): 141-144.

Wachter, R. (2015), The Digital Doctor: Hope, Hype, and Harm at the Dawn of Medicine's Computer Age, New York: McGraw Hill Education.

Weisbrod, B. A. (1991), 'The Health Care Quadrilemma: An Essay on Technological Change, Insurance, Quality of Care, and Cost Containment', Journal of Economic Literature, 29(2): 523-552. 